\title{
Microtubules and cellulose biosynthesis: the emergence of new players
}

Shundai $\mathrm{Li}^{1}$, Lei Lei ${ }^{1}$, Yingling Yaroslava ${ }^{2}$, Ying $\mathrm{Gu}^{1 *}$

${ }^{1}$ Department of Biochemistry and Molecular Biology, Pennsylvania State University,

University Park, PA 16802

2Department of Materials Science and Engineering, North Carolina State University,

Raleigh, NC 27695

*Corresponding author: Email: yug13@psu.edu

$\begin{array}{ll}\text { Abbreviations } \\ \text { CESA } & \text { cellulose synthase } \\ \text { COB } & \text { COBRA } \\ \text { CSC } & \text { cellulose synthase complex } \\ \text { CSI } & \text { cellulose synthase interacting protein } \\ \text { FP } & \text { fluorescent protein } \\ \text { GA } & \text { gibberellic acid } \\ \text { IAA } & \text { indole-3-acetic acid } \\ \text { KOR } & \text { KORRIGAN } \\ \text { MASCs } & \text { microtubule-associated CESA compartments } \\ \text { MIDD } & \text { microtubule depletion domain } \\ \text { MT } & \text { microtubule } \\ \text { SmaCCs } & \text { small CESA compartments }\end{array}$

\begin{abstract}
Microtubules determine the orientation of newly formed cellulose microfibrils in expanding cells. There are many hypotheses regarding how the information is transduced across the plasma membrane from microtubules to cellulose microfibrils. However, the molecular mechanisms underlying the co-alignment between microtubules and cellulose microfibrils were not revealed until the recent discovery of cellulose synthase interacting (CSI) proteins. Characterization of CSIs and additional cellulose synthase-associated proteins will greatly advance the knowledge of how cellulose microfibrils are organized.
\end{abstract}

\section{Introduction}

Plants cells maintain a dynamic cortical microtubule (MT) array at the cell cortex that regulates cell expansion. Cell expansion is a critical determinant of plant organ size and shape. In expanding cylindrical shaped plant cells, transversely oriented cellulose microfibrils, the major load bearing components in the cell wall, restrict radial expansion and promote longitudinal expansion [1]. There has long been a debate over the role of MTs in the guidance of cellulose microfibril orientation [1-6]. Early studies 
suffered from the inability of observing (i) the dynamic reorganization of MTs and microfibrils and (ii) the newest and innermost layer of cellulose microfibrils that is most influenced by the cortical MTs [7,8]. Moreover, the difficulty of adequately sampling dynamic MTs and cellulose microfibrils led to divergent results [9]. Although the guidance of cellulose microfibrils along cortical MTs is not observed in some cell types, like the tip growing cells of root hairs, pollen tubes, fern protonema, and certain algae, MTs do guide cellulose microfibrils in the primary walls of cells undergoing anisotropic growth and in the secondary walls of xylem cells $[4,10]$. This review will divulge the current understanding of the relationship between cellulose microfibrils and cortical MTs by focusing on recent work on the molecular mechanisms underlying the interaction between the integral plasma membrane cellulose biosynthetic machinery, the cellulose synthase complex (CSC), and the cortical MTs.

\section{The dynamics of microtubule and cellulose microfibril reorientation}

MTs are highly dynamic filamentous protein polymers consisting of $\alpha$ - and $\beta$-tubulin heterodimer subunits that undergo cycles of rapid growth and disassembly. Isolated plant tubulins were found to have a greater intrinsic dynamicity than animal tubulins [11]. Although the underlying reason for the increased dynamicity of plant MTs is not well understood, a more dynamic cytoskeleton may have evolved to help plants cope with a sessile lifestyle. Indeed, cortical MTs can change their orientation in response to a variety of signals including light, hormones, gravity, and mechanical stress. Blue light induces a complete MT reorientation from transverse to longitudinal orientation in about 10 minutes whereas it takes 1-2 hour to induce transverse MT organization in response to hormone such as brassinolide, indole-3-acetic acid (IAA) and gibberellic acid (GA4) [12-14]. The mechanism for light-dependent and hormone-induced MT reorientation may be different, with distinct signaling pathways controlling local MT reorientation in a few cells versus large-scale MT patterning in the whole plant. The MT severing protein, katanin, has recently been implicated in blue light induced MT reorientation and another MT associated protein, SPIRAL2, cooperates with katanin to regulate cortical MT arrays in rapidly elongating cells such as leaf petiole epidermal cells [15-17].

MTs also undergo cyclic reorientation presumably following an endogenous rhythm [18]. The entire cortical MT array rotates $360^{\circ}$ within 200-800 min in growing epidermal cells of light-grown Arabidopsis hypocotyls. This rotation appears to be associated with growth because MTs remain in oblique or longitudinal orientations when cells stop elongating. MT orientation could influence growth at least in part by altering the orientation of nascent cellulose microfibrils in the cell wall. Both lightinduced and cyclic MT reorientation occurs in conjunction with a corresponding reorientation of the trajectories of CSCs that are actively synthesizing cellulose [14,19]. Therefore, it is expected that the orientations of nascent cellulose microfibrils change accordingly. CSC trajectory rotation was blocked by drugs that either stabilize or depolymerize MTs, and resulted in the loss of polylamellate cell wall patterns [19], which is consistent with earlier observations that perturbation of MT dynamics affects wall texture [20]. 
Cellulose microfibrils in xylem fibers and tracheids are laid down as three consecutive layers, called S1, S2, and S3 layers. The orientation of cellulose microfibrils switches from a shallow helix in outer $\mathrm{S} 1$ layer (about $40-80^{\circ}$ from the tracheid axis) to a steep helix in S2 layer (about $5-20^{\circ}$ from the tracheid axis) and switches to a shallow helix in the S3 layer at the final stage of secondary wall formation [21]. Similar to the rotation in the orientation of the cellulose microfibrils, successive changes in the orientation of MTs were observed in differentiating conifer tracheids and in the tension wood fibers of hardwoods [22-24]. Because secondary cell wall producing tissues are buried deep within the plant, live cell imaging of CSCs and MTs during secondary wall formation has been hindered by technical difficulties. Although the Zinnia cell culture can circumvent some of these experimental difficulties [25], Zinnia cell cultures lack the genetic and molecular biology tools of Arabidopsis xylem model systems. If the live cell imaging of secondary cell wall producing cells could be improved, insight could be gained in the role of CSCs and MTs controlling the deposition of differentially oriented secondary cell wall layers. The recently developed Arabidopsis xylem system may be key in future studies of CSCs during secondary wall formation [26]. Furthermore, components involved in MT dynamics and cell wall patterning in secondary wall forming cells, such as MIDD1 and MAP70-5, are emerging [27,28].

\section{The connection between microtubules and the cellulose synthesis complex}

The combination of genetics and live cell imaging has greatly improved the understanding of how MTs guide the deposition of cellulose microfibrils. In Arabidopsis, the CSC is made of at least three different cellulose synthase (CESA) proteins in both primary (CESA1, 3 and 6 or 6-like) and secondary cell walls (CESA4, 7 and 8, Table 1). Several fluorescent protein (FP) tagged CESA isoforms (e.g. CESA7, CESA3 or CESA6) are functional in Arabidopsis as indicated by complementation of corresponding cesa mutants $[10,14,29]$. FP-CESAs have been visualized as diffraction-limited particles that move in the plane of the plasma membrane. The movement of the CESA particles is thought to be driven by cellulose synthesis with nascent cellulose microfibrils being deposited along the trajectory of CSC displacement. Formerly, it was proposed that MTs serve as boundaries within which CSCs are constrained to travel [3]. This model has been contradicted by the observation that CSCs travel along MTs $[14,30]$. These observations support the direct guidance model in which CSCs are attached to MTs via direct or indirect interactions, resulting in the parallel alignment between cellulose microfibrils and the underlying MTs [2].

In order to address how CSCs interact with MTs, a yeast two-hybrid screen was performed to identify CESA interacting proteins. Cellulose synthase interacting protein 1 (CSI1) was shown to interact with CESA1, 3, and 6 in a yeast two-hybrid assay [31,32]. In planta, fluorescent protein-tagged CSI1 were shown to colocalize GFP-CESA3 or GFPCESA6 that were actively traveling along MTs [31]. CSI1 was shown to interact with MTs in vitro suggesting a direct association between CSI1 and MTs [33,34]. Although the disassociation constant of CSI1 for MTs was similar to that of conventional MT associated proteins (MAPs) such as MAP65, CSI1 does not contain any conventional MT binding domains [33]. Molecular dynamics simulations indicated that CSI1 protein folds into a long loop-like ribbon structure and developed a model in which the $\mathrm{N}$ - and C- 
termini interact with MTs while the central loop of CSI1 interacts with the CSC to form the link between CSCs and MTs (Figure 1)[35]. Consistent with CSI1 providing the link between CSCs and MTs, loss of CSI1 resulted in the disassociation of CSCs from the underlying MTs in planta [33,36,37]. The dissociation between CSCs and MTs in csi1 null mutants caused defects in the cell expansion of various tissues including dark-grown hypocotyls, roots, siliques, and stems [31]. These phenotypes are likely attributed to defects exclusively in the primary cell wall because: (i) CSI1 interacts with primary CESAs in a yeast two-hybrid assay; (ii) CSI1 is transcriptionally co-regulated with many primary CESAs including CESA1, 3, 5 and 6; (iii) csi1 had no defects in the secondary cell wall that is characterized by a collapse of xylem vessels $[31,38]$.

In addition to CSI1, the Arabidopsis genome encodes two CSI1-like proteins, namely CSI2 and CSI3 [32,38]. While CSI2 might be a pseudogene, CSI3 exhibits many CSI1-like characteristics including the ability to interact with CESA, to co-localize with both CSCs and MTs, and to exhibit CSC-like velocities along MTs. Unlike CSI1, CSI3 is dispensable for the co-alignment of CSCs and MTs in planta. Moreover, ProCSI1::GFP-CSI3 was not able to rescue csi1, suggesting CSI3 is functionally not equivalent to CSI1 [32]. The functional difference between CSI1 and CSI3 was further supported phylogenetic analysis in which CSI1 and CSI3 appear to belong to a different clade (Figure 1). Differences in the expression pattern of CSI3 and CSI1 could also suggest that CSI proteins fulfill similar functions but in different tissues. Nevertheless, CSI1 and CSI3 are present in a variety of dicots, monocots, conifers, and the moss Physcomitrella patens, indicating that CSI proteins might mediate the MT-cellulose interaction throughout the plant kingdom.

In addition to CSI proteins, COBRA and KORRIGAN are both proposed to be involved in the organization of cellulose microfibrils through a MT-related function. COBRA (COB1) encodes a GPI-anchored protein and localizes to MT-like structures (Figure 2) [39,40]. The dependence of COB1 localization on MTs and the disorganization of cellulose microfibrils in cob1 led to a hypothesis that $\mathrm{COB}$ may be responsible for controlling microfibril orientation in a MT-dependent manner [40]. COB1 was also recently shown to bind to individual $\beta-1,4-$ linked glucan chains, but cob1 had no defect in the rate of cellulose polymerization [41]. Brittle culm 1, a COBRA-like protein in rice, also binds crystalline cellulose and modifies cellulose crystallinity [42]. Cellulose microfibril disorganization in cob1 might be attributed to altered cellulose crystallization. KORRIGAN1 (KOR1) encodes a membrane bound $\beta-1,4$ endoglucanase. Arabidopsis KOR1 and its homolog in poplar have been shown to hydrolyze carboxymethyl cellulose and amorphous cellulose in vitro $[43,44]$. Recent studies revealed that KOR1 is likely an integral part of the CSC that travels along MTs with CSCs [45,46]. A novel A577V missense mutation in KOR1 abolished its endoglucanase activity and resulted in both disorganized cellulose microfibrils and MTs, which is consistent with its defect in the organization of CSCs [46]. The concurrent defect in the organization of cortical MTs and organization of CSCs has been observed in kor1-3 [47]. How a defect in cellulose organization affect MTs organization is unknown. It is possible that the cortical microtubule phenotype of kor1 might be attributed to the KOR1's interaction between CSCs and MTs. 


\section{Do microtubules influence any features of cellulose in addition to orientation?}

In addition to guiding the deposition of cellulose microfibrils, MTs also play a role in the intracellular trafficking of CSCs and modulating the velocity of CSCs. CESA containing compartments such as SmaCCs (small CESA compartments) or MASCs (microtubuleassociated CESA compartments) are localized along MTs and exhibit intermittent instances of rapid motility that is driven by MT depolymerization $[48,49]$. These observations are consistent with the hypothesis that SmaCCs/MASCs are involved in assisting the delivery of CSCs along the cortical MTs. Alternatively, SmaCCs/MASCs may function as intracellular storage vesicles of internalized CSCs. The tight association between SmaCCs/MASCs and MTs suggests an important role of cortical MTs in the trafficking of CSCs. Interestingly, the formation of SmaCCs/MASCs is also dependent on intact cortical MTs. This MT-dependent trafficking of CSCs might be mediated through CSI1 since CSI1 is associated with for SmaCCs/MASCs [37]. Many important questions in the formation and function of SmaCCs/MASCs remain to be addressed.

Recent studies suggest that MT mass is inversely correlated with cellulose crystallinity and CSC velocity [50]. It is postulated that the polymerization or crystallization of cellulose microfibrils provides the force to cause CSC movement. MTs are not required to provide the forces to move CSCs as previously postulated [2]. Consistent with this idea, treatment with $200 \mathrm{nM}$ of the MT depolymerizing drug, oryzalin, for over 6 hours does not affect CSC motility [19]. However, prolonged treatment with $20 \mu \mathrm{M}$ oryzalin reduces the motility of CSCs to the same extent as csi1 [33]. These results imply that the reduction in CSC velocity in csi1 might be attributed to a MT-dependent mechanism. However, CSC velocities in csi1 csi3 double mutants is reduced to a greater extent than in csi1 alone where the CSC/MT interaction is already abolished [32], indicating that CSI proteins may also influence CSC velocities in a MT-independent fashion.

Alternatively, MTs have been postulated to direct the formation of plasma membrane micro-domains that could influence the activities of CSCs [51]. It is possible that the organization of CSC-containing specialized lipid micro-domains is dependent on MTs and that the proper function of CSCs is contingent on the integrity of each of these components [52]. Furthermore, certain aspects of the CSC motility appears to be dependent on intact MTs since the asymmetric movement of CSCs in CESA1 phosphorylation mutants is abolished when cortical MTs were removed by oryzalin [53] and the inhibition of velocity of GFP-CESA5 in dark-grown cesa6rc1-1, a null allele of cesa6, was relieved in the presence of oryzalin [54]. However, the detailed mechanisms underlying these phenomena are still unknown.

\section{Perspective}

The emergence of new components involved in the interaction between CSC and MTs provides new opportunities to advance the knowledge of how MTs regulate cellulose biosynthesis. Additionally, genetic and cell biology studies provide evidence that components in or associated with CSCs are capable of regulating MT organization and stability $[46,47,55]$. The function of cortical MTs in plant cells is certainly not limited to 
regulating cellulose synthesis, so the feedback between MTs and the cell wall may potentially be integrated with other MT-related functions. The unique dynamic features of MTs add another layer of complexity to the investigation of the feedback regulation between the cytoskeleton and the cell wall in plants.

\section{Acknowledgement}

Work by investigator Y. Gu was supported by the National Science Foundation (grant \#1121375). Work by investigator Y. Yaroslava was supported by The Center for LignoCellulose Structure and Formation, an Energy Frontier Research Center funded by DOE, Office of Science, BES under Award \# DE-SC0001090.

A

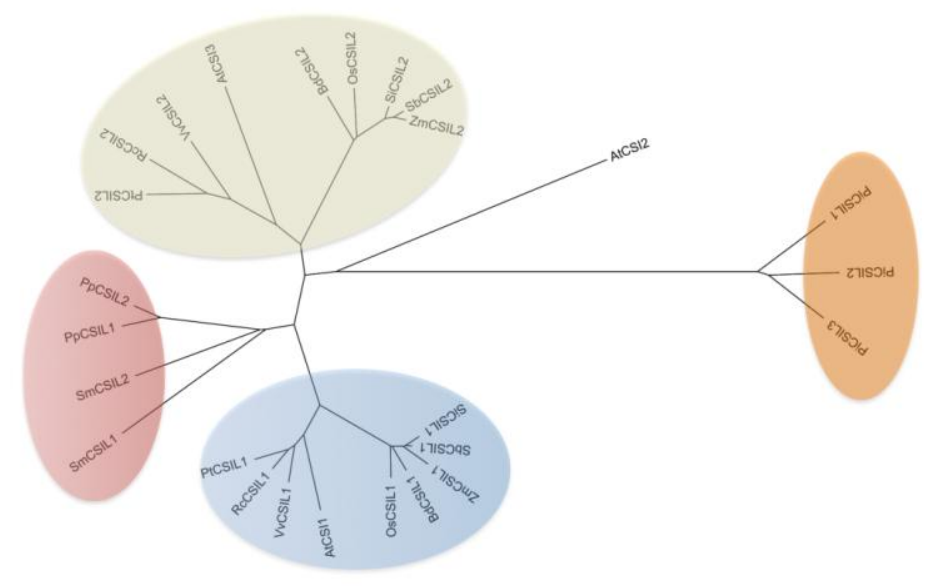

B

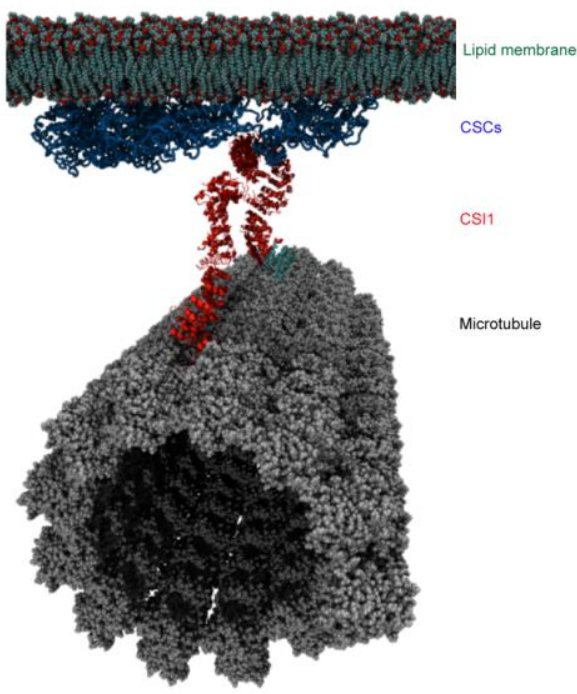

Figure 1. A. Phylogenetic tree of CSI proteins in different species. Abbreviations for prefixes: At: Arabidopsis thaliana, Bd: Brachypodium distachyon, Pi: Phytophthora infestans, Pp: Phycomitrella patens, Pt: Populus trichocarpa, Rc: Ricinus communis, Sb: Sorghum bicolar, Si: Setaria italica, Sm: Selaginella moellendorffil, Os: Oryza sativa, Vv: Vitis vinifera, Zm: Zea mays. B. Putative interaction model of CSI1 with CSCs and microtubules. Only cytoplasmic sides of CSCs are shown. CSI1 protein has extensive alpha-helices shown in red and C-terminus beta sheets shown in blue. 


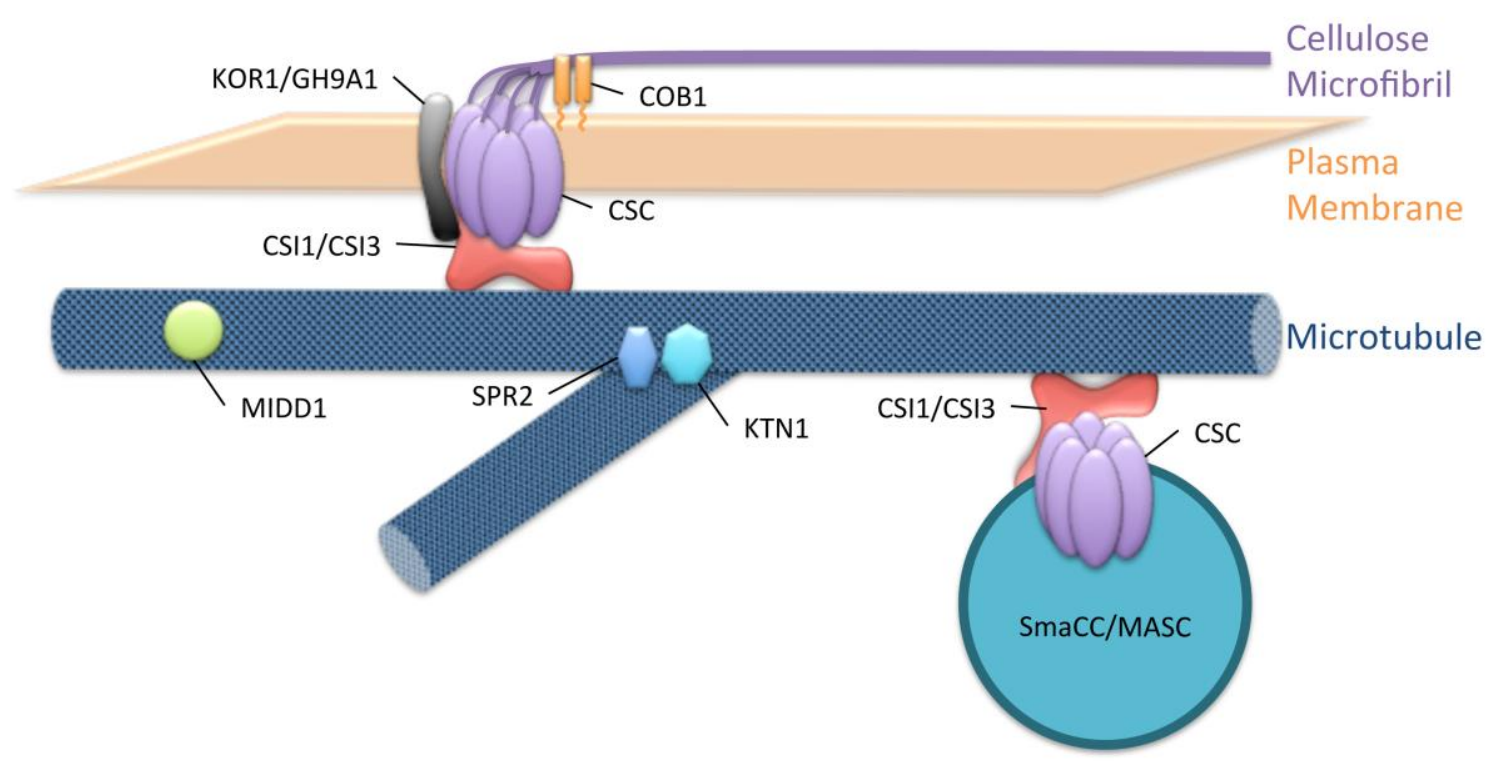

Figure 2. New players involved in the process of cellulose synthesis along the cortical MTs. CSC: Cellulose Synthase Complexes; COB1: COBRA1; CSI1/CSI3: Cellulose Synthase Interacting Protein 1/3; KOR1/GH9A1: KORRIGAN1/Glycosyl Hydrolase Family 9 Class A 1; SPR2: SPIRAL2; KTN1: KATANIN1; SmaCC/MASC: Small CESA-containing Compartments/ Microtubule-associated CESA Compartments.

Table 1. Cellulose synthase complexes in primary cell wall vs. secondary cell wall.

\begin{tabular}{|c|c|c|c|c|c|c|c|}
\hline \multicolumn{4}{|c|}{ Primary CSCs } & \multicolumn{4}{|c|}{ Secondary CSCs } \\
\hline \multicolumn{8}{|c|}{ Integral component } \\
\hline $\begin{array}{l}\text { Composition } \\
\text { CESA1, CESA3, } \\
\text { CESA6 or } \\
\text { CESA6 like }\end{array}$ & $\begin{array}{l}\text { Stoichiometry } \\
1: 1: 1\end{array}$ & $\begin{array}{l}\text { Localization } \\
\text { PM, } \\
\text { SmaCCs/MASCs } \\
\text { Golgi } \\
\text { Cell plate }\end{array}$ & $\begin{array}{l}{[31,48,49} \\
, 54,56- \\
58]\end{array}$ & $\begin{array}{l}\text { Composition } \\
\text { CESA4, CESA7, } \\
\text { CESA8 }\end{array}$ & $\begin{array}{l}\text { Stoichiometry } \\
1: 1: 1\end{array}$ & $\begin{array}{l}\text { Localization } \\
\text { PM, } \\
\text { Golgi }\end{array}$ & {$[10,30,59]$} \\
\hline KORRIGAN1 & N.D. & $\begin{array}{l}\text { PM, } \\
\text { SmaCCs/MASCs, } \\
\text { Golgi } \\
\text { Tonoplast } \\
\text { Cell plate }\end{array}$ & $\begin{array}{l}{[45,46,60} \\
, 61]\end{array}$ & KORRIGAN1 & N.D. & N.D. & \\
\hline \multicolumn{8}{|c|}{ Associated protein } \\
\hline CSI1, CSI3 & N.D. & $\begin{array}{l}\text { PM, } \\
\text { SmaCCs/MASCs }\end{array}$ & $\begin{array}{l}{[31-} \\
33,36,37]\end{array}$ & N.D. & & & \\
\hline
\end{tabular}

\section{Reference}

1. Green PB: Mechanism for Plant Cellular Morphogenesis. Science 1962, 138:14041405.

2. Heath IB: A unified hypothesis for the role of membrane bound enzyme complexes and microtubules in plant cell wall synthesis. J Theor Biol 1974, 48:445-449. 
3. Giddings TH, Staehelin LA: Microtubule-mediated control of microfibril deposition: a re-examination of the hypothesis. In The cytoskeletal basis of plant growth and form. Edited by CW L: Academic; 1991:85-99.

4. Baskin TI: On the alignment of cellulose microfibrils by cortical microtubules: a review and a model. Protoplasma 2001, 215:150-171.

5. Lloyd C, Chan J: The parallel lives of microtubules and cellulose microfibrils. Curr Opin Plant Biol 2008, 11:641-646.

6. Wasteneys GO: Progress in understanding the role of microtubules in plant cells. Curr Opin Plant Biol 2004, 7:651-660.

7. Crowell EF, Timpano H, Desprez T, Franssen-Verheijen T, Emons AM, Hofte H, Vernhettes S: Differential regulation of cellulose orientation at the inner and outer face of epidermal cells in the Arabidopsis hypocotyl. Plant Cell 2011, 23:2592-2605.

8. Chan J, Eder M, Crowell EF, Hampson J, Calder G, Lloyd C: Microtubules and CESA tracks at the inner epidermal wall align independently of those on the outer wall of light-grown Arabidopsis hypocotyls. J Cell Sci 2011, 124:1088-1094.

9. O'Brien TPO: The cytology of cell-wall formation in some eukaryotic cells. Bot Rev 1972, 38:87-118.

10. Gardiner JC, Taylor NG, Turner SR: Control of cellulose synthase complex localization in developing xylem. Plant Cell 2003, 15:1740-1748.

11. Shaw SL, Kamyar R, Ehrhardt DW: Sustained microtubule treadmilling in Arabidopsis cortical arrays. Science 2003, 300:1715-1718.

12. Vineyard L, Elliott A, Dhingra S, Lucas JR, Shaw SL: Progressive transverse microtubule array organization in hormone-induced Arabidopsis hypocotyl cells. Plant Cell 2013, 25:662-676.

13. Wang XL, Zhang J, Yuan M, Ehrhardt DW, Wang ZY, Mao TL: Arabidopsis MICROTUBULE DESTABILIZING PROTEIN40 Is Involved in Brassinosteroid Regulation of Hypocotyl Elongation. Plant Cell 2012, 24:4012-4025.

14. Paredez AR, Somerville CR, Ehrhardt DW: Visualization of cellulose synthase demonstrates functional association with microtubules. Science 2006, 312:1491-1495.

15. Lindeboom JJ, Nakamura M, Hibbel A, Shundyak K, Gutierrez R, Ketelaar T, Emons AM, Mulder BM, Kirik V, Ehrhardt DW: A mechanism for reorientation of cortical microtubule arrays driven by microtubule severing. Science 2013, 342:1245533.

16. Wightman R, Chomicki G, Kumar M, Carr P, Turner SR: SPIRAL2 determines plant microtubule organization by modulating microtubule severing. Curr Biol 2013, 23:1902-1907.

17. Wightman R, Turner SR: A novel mechanism important for the alignment of microtubules. Plant Signal Behav 2008, 3:238-239.

18. Chan J, Calder G, Fox S, Lloyd C: Cortical microtubule arrays undergo rotary movements in Arabidopsis hypocotyl epidermal cells. Nat Cell Biol 2007, 9:171-175.

19. Chan J, Crowell E, Eder M, Calder G, Bunnewell S, Findlay K, Vernhettes S, Hofte H, Lloyd C: The rotation of cellulose synthase trajectories is microtubule 
dependent and influences the texture of epidermal cell walls in Arabidopsis hypocotyls. J Cell Sci 2010, 123:3490-3495.

20. Lloyd C: Dynamic microtubules and the texture of plant cell walls. Int Rev Cell Mol Biol 2011, 287:287-329.

21. Funada R: Microtubules and the control of wood formation. In Plant Cell Monographs: Plant Microtubules. Edited by P N: Springer; 2008:83-119.

22. Abe H, Funada R, Ohtani J, Fukazawa K: Changes in the arrangement of microtubules and microfibrils in differentiating conifer tracheids during the expansion of cells. Ann Bot 1995, 75:305-310.

23. Chaffey N, Barlow $\mathrm{P}$, Sundberg B: Understanding the role of the cytoskeleton in wood formation in angiosperm trees: hybrid aspen (Populus tremula $\mathbf{x}$. tremuloides) as the model species. Tree Physiol 2002, 22:239-249.

24. Prodhan A, Funada R, Ohtan J, Abe H, Fukazawa K: Orientation of microfibrils and microtubules in developing tension-wood fibers of Japanese ash (Fraxinus mandshurica var. japonica). Planta 1995, 196:577-585.

25. Ohdaira Y, Kakegawa K, Amino S, Sugiyama M, Fukuda H: Activity of cell-wall degradation associated with differentiation of isolated mesophyll cells of Zinnia elegans into tracheary elements. Planta 2002, 215:177-184.

26. Kondo Y, Fujita T, Sugiyama M, Fukuda H: A Novel System for Xylem Cell Differentiation in Arabidopsis thaliana. Molecular plant 2015, 8:612-621.

27. Oda Y, Fukuda H: Initiation of cell wall pattern by a Rho- and microtubuledriven symmetry breaking. Science 2012, 337:1333-1336.

28. Pesquet E, Korolev AV, Calder G, Lloyd CW: The microtubule-associated protein AtMAP70-5 regulates secondary wall patterning in Arabidopsis wood cells. Curr Biol 2010, 20:744-749.

29. Desprez T, Juraniec M, Crowell EF, Jouy H, Pochylova Z, Parcy F, Hofte H, Gonneau M, Vernhettes $S$ : Organization of cellulose synthase complexes involved in primary cell wall synthesis in Arabidopsis thaliana. Proc Natl Acad Sci USA 2007, 104:15572-15577.

30. Wightman R, Turner SR: The roles of the cytoskeleton during cellulose deposition at the secondary cell wall. Plant J 2008, 54:794-805.

31. Gu Y, Kaplinsky N, Bringmann M, Cobb A, Carroll A, Sampathkumar A, Baskin TI, Persson $S$, Somerville CR: Identification of a cellulose synthase-associated protein required for cellulose biosynthesis. Proc Natl Acad Sci USA 2010, 107:12866-12871.

32. Lei L, Li S, Du J, Bashline L, Gu Y: CELLULOSE SYNTHASE INTERACTIVE3 Regulates Cellulose Biosynthesis in Both a Microtubule-Dependent and MicrotubuleIndependent Manner in Arabidopsis. Plant Cell 2013, 25:4912-4923.

33. Li S, Lei L, Somerville C, Gu Y: Cellulose synthase interacting protein 1 (CSI1) links microtubules and cellulose synthase complexes. Proc Natl Acad Sci USA 2012, 109:185-190.

34. Mei Y, Gao H, Yuan M, Xue H: The arabidopsis ARCP protein, CSI1, which is required for microtubule stability, is necessary for root and anther development. Plant Cell 2012, 24:1066-1080. 
35. Lei L, Singh A, Bashline A, Li S, Yingling YG, Gu Y: The Arabidopsis cellulose synthase interactive 1 is required for a fast recycling of cellulose synthase complex to the plasma membrane. Plant Cell 2015.

36. Bringmann M, Li E, Sampathkumar A, Kocabek T, Hauser MT, Persson S: POMPOM2/cellulose synthase interacting1 is essential for the functional association of cellulose synthase and microtubules in Arabidopsis. Plant Cell 2012, 24:163-177.

37. Lei L, Li S, Gu Y: Cellulose synthase interactive protein 1 (CSI1) mediates the intimate relationship between cellulose microfibrils and cortical microtubules. Plant Signal Behav 2012, 7:714-718.

38. Gu Y, Somerville C: Cellulose synthase interacting protein: a new factor in cellulose synthesis. Plant Signal Behav 2010, 5:1571-1574.

39. Schindelman G, Morikami A, Jung J, Baskin TI, Carpita NC, Derbyshire P, McCann MC, Benfey PN: COBRA encodes a putative GPI-anchored protein, which is polarly localized and necessary for oriented cell expansion in Arabidopsis. Genes Dev 2001, 15:1115-1127.

40. Roudier F, Fernandez AG, Fujita M, Himmelspach R, Borner GH, Schindelman G, Song S, Baskin TI, Dupree P, Wasteneys GO, et al.: COBRA, an Arabidopsis extracellular glycosyl-phosphatidyl inositol-anchored protein, specifically controls highly anisotropic expansion through its involvement in cellulose microfibril orientation. Plant Cell 2005, 17:1749-1763.

41. Sorek N, Sorek H, Kijac A, Szemenyei HJ, Bauer S, Hematy K, Wemmer DE, Somerville CR: The Arabidopsis COBRA protein facilitates cellulose crystallization at the plasma membrane. J Biol Chem 2014, 289:34911-34920.

42. Liu L, Shang-Guan K, Zhang B, Liu X, Yan M, Zhang L, Shi Y, Zhang M, Qian Q, Li J, et al.: Brittle Culm1, a COBRA-like protein, functions in cellulose assembly through binding cellulose microfibrils. PLoS Genet 2013, 9:e1003704.

43. Liebminger E, Grass J, Altmann F, Mach L, Strasser R: Characterizing the link between glycosylation state and enzymatic activity of the endo-beta1,4glucanase KORRIGAN1 from Arabidopsis thaliana. J Biol Chem 2013, 288:22270-22280.

44. Master ER, Rudsander UJ, Zhou W, Henriksson H, Divne C, Denman S, Wilson DB, Teeri TT: Recombinant expression and enzymatic characterization of PttCel9A, a KOR homologue from Populus tremula $x$ tremuloides. Biochemistry 2004, 43:10080-10089.

45. Vain T, Crowell EF, Timpano H, Biot E, Desprez T, Mansoori N, Trindade LM, Pagant S, Robert $\mathrm{S}$, Hofte $\mathrm{H}$, et al.: The Cellulase KORRIGAN Is Part of the Cellulose Synthase Complex. Plant Physiol 2014, 165:1521-1532.

46. Lei L, Zhang T, Strasser R, Lee CM, Gonneau M, Mach L, Vernhettes S, Kim SH, D JC, Li $S$, et al.: The jiaoyao1 Mutant Is an Allele of korrigan1 That Abolishes Endoglucanase Activity and Affects the Organization of Both Cellulose Microfibrils and Microtubules in Arabidopsis. Plant Cell 2014, 26:2601-2616.

47. Paredez AR, Persson S, Ehrhardt DW, Somerville CR: Genetic evidence that cellulose synthase activity influences microtubule cortical array organization. Plant Physiol 2008, 147:1723-1734. 
48. Crowell EF, Bischoff V, Desprez T, Rolland A, Stierhof YD, Schumacher K, Gonneau M, Hofte H, Vernhettes S: Pausing of Golgi bodies on microtubules regulates secretion of cellulose synthase complexes in Arabidopsis. Plant Cell 2009, 21:1141-1154.

49. Gutierrez R, Lindeboom JJ, Paredez AR, Emons AM, Ehrhardt DW: Arabidopsis cortical microtubules position cellulose synthase delivery to the plasma membrane and interact with cellulose synthase trafficking compartments. Nat Cell Biol 2009, 11:797-806.

50. Fujita M, Himmelspach R, Hocart CH, Williamson RE, Mansfield SD, Wasteneys GO:

Cortical microtubules optimize cell-wall crystallinity to drive unidirectional growth in Arabidopsis. Plant J 2011, 66:915-928.

51. Fujita M, Lechner B, Barton DA, Overall RL, Wasteneys GO: The missing link: do cortical microtubules define plasma membrane nanodomains that modulate cellulose biosynthesis? Protoplasma 2012, 249 Suppl 1:S59-67.

52. Lei L, Li S, Bashline L, Gu Y: Dissecting the molecular mechanism underlying the intimate relationship between cellulose microfibrils and cortical microtubules. Front Plant Sci 2014, 5:90.

53. Chen S, Ehrhardt DW, Somerville CR: Mutations of cellulose synthase (CESA1) phosphorylation sites modulate anisotropic cell expansion and bidirectional mobility of cellulose synthase. Proc Natl Acad Sci USA 2010, 107:17188-17193.

54. Bischoff V, Desprez T, Mouille G, Vernhettes S, Gonneau M, Hofte H: Phytochrome Regulation of Cellulose Synthesis in Arabidopsis. Curr Biol 2011, 21:18221827.

55. Fisher DD, Cyr RJ: Extending the Microtubule/Microfibril paradigm. Cellulose synthesis is required for normal cortical microtubule alignment in elongating cells. Plant Physiol 1998, 116:1043-1051.

56. Paradez A, Wright A, Ehrhardt DW: Microtubule cortical array organization and plant cell morphogenesis. Curr Opin Plant Biol 2006, 9:571-578.

57. Gonneau M, Desprez T, Guillot A, Vernhettes S, Hofte H: Catalytic subunit stoichiometry within the cellulose synthase complex. Plant Physiol 2014, 166:1709-1712.

58. Miart F, Desprez T, Biot E, Morin H, Belcram K, Hofte H, Gonneau M, Vernhettes S: Spatio-temporal analysis of cellulose synthesis during cell plate formation in Arabidopsis. Plant J 2014, 77:71-84.

59. Hill JL, Jr., Hammudi MB, Tien M: The Arabidopsis cellulose synthase complex: a proposed hexamer of CESA trimers in an equimolar stoichiometry. Plant Cell 2014, 26:4834-4842.

60. Robert S, Bichet A, Grandjean O, Kierzkowski D, Satiat-Jeunemaitre B, Pelletier S, Hauser MT, Hofte H, Vernhettes S: An Arabidopsis endo-1,4-beta-D-glucanase involved in cellulose synthesis undergoes regulated intracellular cycling. Plant Cell 2005, 17:3378-3389.

61. Zuo J, Niu QW, Nishizawa N, Wu Y, Kost B, Chua NH: KORRIGAN, an Arabidopsis endo-1,4-beta-glucanase, localizes to the cell plate by polarized targeting and is essential for cytokinesis. Plant Cell 2000, 12:1137-1152. 
${ }^{*}$ special interest

Lei L, Li S, Du J, Bashline L, Gu Y: CELLULOSE SYNTHASE INTERACTIVE3 Regulates Cellulose Biosynthesis in Both a Microtubule-Dependent and MicrotubuleIndependent Manner in Arabidopsis. Plant Cell 2013, 25:4912-4923.

This work demonstrates that CSI3 is dispensable for co-alignment between CSCs and microtubules although it shares many CSI1-like features. It is an important discovery that both microtubule-dependent function and microtubuleindependent function are required to maintain the proper rates of cellulose biosynthesis.

Sorek N, Sorek H, Kijac A, Szemenyei HJ, Bauer S, Hematy K, Wemmer DE, Somerville CR: The Arabidopsis COBRA protein facilitates cellulose crystallization at the plasma membrane. J Biol Chem 2014, 289:34911-34920.

In this study, COBRA was shown to bind individual glucan chains. Lesion in COBRA resulted in less crystalline cellulose but normal celluose polymerization rate. Authors propose that COBRA facilitates the crystallization of celluose microfibril

Bringmann M, Li E, Sampathkumar A, Kocabek T, Hauser MT, Persson S: POMPOM2/cellulose synthase interacting1 is essential for the functional association of cellulose synthase and microtubules in Arabidopsis. Plant Cell 2012, 24:163-177.

Authors characterized POM2, which is allelic to CSI1. pom2 displays microtubulerelated phenotypes but it does not influence CSC insertion along the microtubules. By comparing the co-localization of CSCs and microtubules in wild type and pom 2 mutant, authors revealed that POM2 is essential for the coalignment between CSCs and microtubules.

Crowell EF, Timpano H, Desprez T, Franssen-Verheijen T, Emons AM, Hofte H, Vernhettes S: Differential regulation of cellulose orientation at the inner and outer face of epidermal cells in the Arabidopsis hypocotyl. Plant Cell 2011, 23:2592-2605.

Authors discovered that both microtubules organization and CSC trajectories at the outer epidermal wall were mixed on the epidermal cells of etiolated hypocotyls. By contrast, cellulose microfibrils and cortical microtubules have a predominant transverse orientation at the inner surface of the epidermis.

Chan J, Eder M, Crowell EF, Hampson J, Calder G, Lloyd C: Microtubules and CESA tracks at the inner epidermal wall align independently of those on the outer wall of light-grown Arabidopsis hypocotyls. J Cell Sci 2011, 124:1088-1094. 
Authors observed that both microtubules and CESA tracks have different alignments in different cells and that the alignment also differ between inner and outer surfaces of the same cell in light grown hypocotyls. The regulation of growth anisotropy is attributed to the organization of microtubles on the inner walls.

** outstanding interest

Gu Y, Kaplinsky N, Bringmann M, Cobb A, Carroll A, Sampathkumar A, Baskin TI, Persson S, Somerville CR: Identification of a cellulose synthase-associated protein required for cellulose biosynthesis. Proc Natl Acad Sci USA 2010, 107:12866-12871.

Authors identifed CSI1 as the first CESA interactive protein using yeast two hybrid assay. CSI1 localizes to the plasma membrane and moves in linear trajectories that coincide with that of CESA. csi1 null mutants display cell expansion defects that correlate with deficiency in crystalline cellulose content.

Li S, Lei L, Somerville C, Gu Y: Cellulose synthase interacting protein 1 (CSI1) links microtubules and cellulose synthase complexes. Proc Natl Acad Sci USA 2012, 109:185-190.

This study established the function of CSI1 as a linker between CSCs and microtubules. CSI1 directly interacted with CESA in a yeast two-hybrid assay and it directly interacted with microtubules in vitro. Supporting the role of CSI1 as a linker protein, csi1 null mutant disrupted the association between CSCs and microtubules.

Vain T, Crowell EF, Timpano H, Biot E, Desprez T, Mansoori N, Trindade LM, Pagant S, Robert S, Hofte H, et al.: The Cellulase KORRIGAN Is Part of the Cellulose Synthase Complex. Plant Physiol 2014, 165:1521-1532.

Authors demenstrated KORRIGAN1 is an integral part of CSCs by live imaging of KOR1 and CSCs, by co-purifiying KOR1 and CSCs in a high molecular mass protein complex, and by showing direct interaction using split ubiquitin yeast two-hybrid assay and bimolecular fluorescence complementation.

Lei L, Zhang T, Strasser R, Lee CM, Gonneau M, Mach L, Vernhettes S, Kim SH, D JC, Li $S$, et al.: The jiaoyao1 Mutant Is an Allele of korrigan1 That Abolishes Endoglucanase Activity and Affects the Organization of Both Cellulose Microfibrils and Microtubules in Arabidopsis. Plant Cell 2014, 26:2601-2616.

Authors identified a novel A577V missense mutation in KORRIGAN1. K0R1A577V abolished the endoglucanase activity of KOR1 and led to more transversely 
oriented cellulose microfibrils and disorganized microtubules. This study suggests the potential for discovery of additional role for KOR1 in plant development and cellulose synthesis. 